\title{
Implementation of PBL in Engineering Education: Conceptualization and Management of Tensions
}

\author{
Angela van Barneveld ${ }^{1}$ and Johannes Strobel ${ }^{2}$ \\ ${ }^{1}$ Purdue University/Lakehead University ${ }^{2}$ Texas A\&M University \\ evanbarn@purdue.edu
}

\begin{abstract}
Engineering educators are facing high demands as they are being challenged to create learning environments that not only better teach technical skills, but also incorporate process skills and foster other desirable attributes. Problem-based learning, known as $P B L$, and its variants have been deemed effective as an instructional strategy in a variety of different disciplines including engineering. With pedagogical innovations like PBL, however, comfortable routines related to the structure and flow of classroom activity is disrupted for both educators and students. In addition to having to manage changes within their classroom processes and routines, engineering educators must also interact and operate within the larger systems in which their classrooms are embedded, the university. The structure and culture of the university system may facilitate or hinder the teaching intentions and goals of educators, as this larger system can impose its own set of tensions. In this paper, we report findings of a research study which investigated conceptualizations of $P B L$, tensions as experienced when implementing PBL and strategies to manage the tensions.
\end{abstract}

Keywords: engineering education, innovative pedagogy, PBL, problem-based learning, tensions

\section{INTRODUCTION}

Problem-based learning is a widely used and proven instructional strategy to teach complex competencies in an open-ended and scaffolded learning environment, yet instructors face often obstacles and tensions in implementing $\mathrm{PBL}$ in the engineering classrooms. Of particular interest in this study is the implementation of PBL and management of tensions in the early years of the engineering program. Often, PBL variants such as capstone design projects are implemented in later years of an engineering program so that students have the opportunity to apply the foundational engineering and science and mathematics knowledge they acquired earlier in the curriculum [1][2][3]. However, engineering faculty have recognized and acknowledged the need to implement problem-based pedagogies earlier in the program [4] to provide early opportunities to develop and integrate technical skills, process skills (e.g., problem solving skills, communication and teamwork skills) [5][6]; to demonstrate linkages between course content and real life engineering [7]; to prepare students to understand the role of engineers in society [8]; and to increase student retention in engineering programs [9].

The purpose of this study was to describe, based on interview data, the variation in engineering educators' ways of experiencing tensions in PBL implementations, as well as how they managed the tensions encountered. In the specific context of the first two years of undergraduate engineering education in the United States, the research questions were:

1. What are the qualitatively different ways in which engineering educators experience tensions with a PBL implementation in their teaching practice?

2. How do engineering educators manage these tensions?

\section{LITERATURE}

\subsection{Problem-oriented Pedagogy}

Problem-based learning, a learner-centered pedagogy, has been brought into the realm of engineering education under various names - problem-based learning (PBL) [1][10], project-based learning (PjBL) [11][4], and problem-oriented project-based learning (POPBL) [12]. The call for increased design-based curriculum in engineering education [13] is also reflected in newer curriculum strategies such as Conceive-DesignImplement-Operate (CDIO) [14]. The effectiveness of problem-based pedagogies has been demonstrated for long-term knowledge retention, skill development, student and faculty satisfaction [15] including in the domain of engineering [16], as well as increased motivation and engagement of students, increased self- 
directed learning skills, and an increased integration of theory and practice [17] .

In the pursuit of reform, the role of engineering faculty as the implementers of pedagogical change becomes critical [18]. They are, to a large extent, the instigators of reform within their classrooms and the implementers of innovative pedagogical approaches. Most engineering educators implement PBL of their own accord and in an incremental fashion [19]. The adoption of PBL by engineering educators is important to its establishment in engineering education and necessitates a new way of conceptualizing teaching and learning. Schneckenberg argued, though, that faculty faced tensions within the various levels of the embedded systems and contexts in which they found themselves as they considered the adoption of innovations [20].

\subsection{Tensions that Faculty Encounter}

In higher education. Despite faculty having significant autonomy within their classrooms and teaching/research practices, it is important to understand that their classes/courses are embedded within a larger system and culture. The larger system has the potential to support or constrain the efforts of the individual faculty members. Barriers that impact adoption of innovations can be structural or cultural. Structural barriers are related to the status and priorities of faculty, while cultural barriers are related to the basic values of teaching and research within the institution [20]. Tensions exist between the desired outcomes of education and the affordances that actually exist within the institutional system.

With the adoption of pedagogical innovations. The adoption of an educational innovation, whether technological or pedagogical, involves some degree of disruption to familiar routines and teaching habits. The adoption of more learner-centered, teacher-facilitated designs require a shift in teacher-student roles, processes of learning, and the design of learning materials. Canavan [23] described the tensions as an apparent conflict between strategic influences (traditional - less time, less effort) and the recognition of the attributes of PBL (deeper learning, authentic). The values and culture of the larger system may produce tensions where innovation is implemented.

With PBL. Hung et al. [21] identified and described five tensions of PBL. These include depth versus breadth of curriculum, higher-order thinking versus factual knowledge acquisition, long-term effects versus immediate learning outcomes, student's initial discomfort versus their subsequent positive attitudes, and the traditional role of instructor versus the role of facilitator.

With engineering education reform. While Hung et al. [21] identified PBL tensions in general, other researchers identified tensions specific to engineering education reform. These include individual versus organization value assigned to teaching [14][27], theory versus practice/application [22], classroom problems (well-structured) versus real-world problems (illstructured) [24], single-disciplinary versus interdisciplinary content [16], problem-solving versus design [24].

The introduction of an innovative pedagogy such as PBL brings with it a set of tensions [21] and compounds the tensions already identified in engineering education reform efforts [14]. How engineering educators conceptualize and manage these tensions remains largely unexplored.

\section{METHODS}

This qualitative study contained two phases of research. The first was a survey that provided descriptive data about respondents (engineering educators) and their experiences with PBL implementations. The purpose of this phase was to create a pool from which to select a smaller subset of engineering educators for interviews. The second phase was a qualitative, phenomenographic study that, through the use of cases, explored the experiences, conceptions, and practices of engineering educators who have implemented PBL within their classroom practices. Phenomenography is a research framework that focuses on the relationship between a phenomenon and people's conception of the phenomenon. The object of study is the collective variation of the human experience of a phenomenon, not the phenomenon itself. The intent is to capture, understand, and describe individuals' conceptions/ experiences of the phenomenon (second-order perspective) rather than the phenomenon itself (first-order perspective) [25]. The emphasis is on understanding and describing not only the commonalities, but more so the variation in the individuals' ways of seeing and experiencing the phenomenon [26].

For this study, the phenomenon studied was the conceptualization of tensions in a PBL implementation in engineering education, and the unit of analysis was the individual educator's conception of the phenomenon. Fourteen US educators implementing PBL in early program years (Yr1 and Yr2) were interviewed about the tensions encountered and management strategies they implemented.

\subsection{Data Collection}

One month of data collection resulted in 427 usable surveys, 313 of which were for US engineering educators. While the focus of the final research was on a US sample, the larger dataset indicated that American and Canadian engineering educators identified the similar primary tensions at the course and system level. Preliminary survey results are discussed in a previous conference 
paper [28] where data from only 30 Canadian educators was available.

\section{RESULTS and DISCUSSION}

While all tensions were touched upon to some extent by interviewees, three tensions elicited the greatest amount of conversation from the engineering educators: student discomfort with the initial transition to PBL, the role of the educator as facilitator rather than teacher, and the value assigned to teaching by the individual and the organization.

Student discomfort with the transition to $P B L$ versus positive attitudes once the transition is made. Educators' conceptualization of this tension generated the most conversation from interview participants who, in the early years of the engineering program, had to address student entry into and expectations of the higher education learning environment. The variations in their conceptualizations generated three categories of description that represent the increasingly complex ways of understanding the discomfort of students as they transition into a new way of learning and into higher education: (1) Student discomfort as a lack of readiness with regard to knowledge, skills, and attitude; (2) Student discomfort as dissonance of student expectations between their old learning environment and their new learning environment; and (3) Student discomfort as a transition to the new learning environment (PBL). Management strategies included (1) helping students understand the new learning environment by setting expectations and providing orientation, and (2) supporting the transition by tailoring the activities to the level of the learner, including class structure, use of scaffolds and feedback, and revising problem boundaries and constraints.

Traditional role as instructor versus facilitator. With regard to how engineering educators in this study understood the tension of instructor versus facilitator, three categories of description emerged. These categories demonstrated not only the progression from a narrower conceptualization of one's role (content provider) to a more evolved conceptualization (identity formation), but also demonstrated the hierarchical relationship between what one knows, what one does, and who one is. This tension was conceptualized as educator as (1) content provider, (2) process advocate, and (3) learning (re)constructivist. Management strategies included (1) shifting the relationship between the instructor, the student, and the content, and (2) optimizing the instructor's role and their use of time.

Individual versus organizational value assigned to teaching. Three categories of description emerged, each depicting variation in the experience of the tension as well as a relationship between categories that represented the increasingly complex ways of understanding the phenomenon - the tension between the individual and the organizational value assigned to teaching. These were (1) indifference, described as superficial support and lack of acknowledgment of required effort, (2) skepticism, described as pressure to conform to traditional teaching practices and focus on immediate vs long-term learning outcomes, and content over process; and (3) misalignment between the implementation innovative pedagogies/ teaching practices with the evaluation of instructors and the culture of tradition in engineering education. Interestingly, these educators offered no management strategies address this tension other to indicate that they ignored it. They did what they thought was in the best interest of their students and of the engineering profession.

\section{IMPLICATIONS FOR PRACTICE}

This study contributes to the body of knowledge of engineering education research, scholarship of teaching and learning, and problem-based learning. For engineering educators considering the implementation of PBL into their teaching practice, this study offered not only insights into potential tensions, but also the management strategies used to mitigate the tension. Additionally, this study revealed the complexities of the interaction between student, educator, and pedagogy and the need to anticipate and support transformation of the learner and the educator when engaged in a studentcentered, active learning environment.

For administrators, consideration may be given to establishing strategies and policies that support and encourage the implementation of innovative pedagogies, including recognition of the required effort and reward.

For faculty development professionals, consideration for design and development of professional development programs may include the two levels impacted by the implementation of innovative pedagogies (like PBL), the classroom level and the system level.

For engineering educators who are planning to implement PBL, this study offers insights into tensions that may occur at various levels of the academy as well strategies to manage those tensions.

\section{References}

[1] Brodie, L., Zhou, H., \& Gibbons, A. (2008). Steps in developing an advanced software engineering course using problem based learning. Engineering Education, 3(1), 2-12.

[2] Mitchell, J. E. \& Smith, J. (2008). Case study of the introduction of problem-based learning into electrical engineering. International Journal of Electrical Engineering Education, 45(2), 131-143. 
[3] Nasr, K. J. \& Ramadan, B. H. (2008). Impact assessment of problem-based learning in an engineering science course. Journal of STEM Education, 9(3/4), 16-24.

[4] Lima, R. M., Carvalho, D., Flores, M. A., \& van Hattum-Janssen, N. (2007). A case study on project led education in engineering: Students' and teachers' perceptions. European Journal of Engineering Education, 32(3), 337-347. doi: 10.1080/03043790701278599.

[5] Simcock, A., Shi, J., \& Thorn, R. (2008, December). Using real industry problems to engage PBL students. Paper presented at the 2008 AaeE Conference, Yeppoon, AUS.

[6] Town, G. E. \& McGill, D. (2008, December). Development of a new foundation unit in engineering. Paper presented at the 2008 AaeE Conference, Yeppoon, AUS.

[7] Güzeliş, C. (2006). An experience on problem-based learning in an engineering faculty. Turkish Journal of Electrical Engineering, 14(1), 67-76.

[8] Hsieh, C. \& Knight, L. (2008). Problem-based learning for engineering students: An evidence-based comparative study. Journal of Academic Librarianship, 34(1), 25-30.

[9] Savage, R. N., Chen, K. C., \& Vanasupa, L. (2007). Integrating project-based learning throughout the undergraduate engineering curriculum. Journal of STEM Education Innovations \& Research, 8(3/4), 1527.

[10] Butun, E., Erkin, H. C., \& Altintas, L. (2008). A new teamwork-based PBL problem design for electrical and electronic engineering education: a systems approach. International Journal of Electrical Engineering Education, 45(2), 110-229.

[11] Edward, N. (2004). Evaluations of introducing project-based design activities in the first and second years of engineering courses. European Journal of Engineering Education, 29(4), 491-503.

[12] Lehmann, M., Christensen, P., Du, X., \& Thrane, M. (2008). Problem-oriented and project-based learning (POPBL) as an innovative learning strategy for sustainable development in engineering education.
European Journal of Engineering Education, 33(3), 283-295. doi: 10.1080/03043790802088566.

[13] Sheppard, S. D., Macatangay, K., Colby, A., \& Sullivan, W. M. (2009). Educating engineers: Designing for the future of the field. San Francisco, CA: Jossey-Bass.

[14] Crawley, E. F., Malmqvist, J., Östlund, S., \& Brodeur, D. R. (2007). Rethinking engineering education: The CDIO approach. New York, NY: Springer.

[15] Strobel, J. \& van Barneveld, A. (2009). When is PBL more effective? A meta-synthesis of metaanalyses comparing PBL to conventional classrooms. Interdisciplinary Journal of Problem-based Learning, 3(1), 44-58.

[16] Froyd, J., Li, X., Srinivasa, A., Bassichis, W., Hodge, J., \& Maxwell, D. (2006, June). How do students in a project-based first-year engineering curriculum perform in a sophomore engineering mechanics course? Paper presented at the 2006 ASEE Annual Conference \& Exposition, Chicago, IL. http://soa.asee.org/paper/conference/paperview.cfm?id=1319.

[17] Ribeiro, L. R. C. (2008). Electrical engineering students evaluate problem-based learning (PBL). International Journal of Electrical Engineering Education, 45(2), 152-312.

[18] Barr, R. B. \& Tagg, J. (1995). From teaching to learning - a new paradigm for undergraduate education. Change, 27(6), 12-25.

[19] Inderbitzin, M. \& Storrs, D. A. (2008). Mediating the conflict between transformative pedagogy and bureaucratic practice. College Teaching, 56(1), 47-52.

[20] Schneckenberg, D. (2009). Understanding the real barriers to technology-enhanced innovation in higher education. Educational Research, 51(4), 411-424. doi: 10.1080/00131880903354741.

[21] Hung, W., Bailey, J. H., \& Jonassen, D. H. (2003). Exploring the tensions of problem-based learning: Insights from research. New Directions for Teaching \& Learning, 95, 13-23.

[22] Mills, J. E. \& Treagust, D. F. (2003). Engineering education - Is problem-based learning or project-based 
learning the answer? Australasian Journal of Engineering Education, 2-16.

[23] Canavan, B. (2008). A summary of the findings from an evaluation of problem-based learning carried out at three UK universities. International Journal of Electrical Engineering Education, 45(2), 175-180.

[24] Holt, J. E., Radcliffe, D. F., \& Schoorl, D. (1985). Design or problem solving - a critical choice for the engineering profession. Design Studies, 6(2), 107-110.

[25] Tutty, J., Sheard, J., \& Avram, C. (2008). Teaching in the current higher education environment: Perceptions of IT academics. Computer Science Education, 18(3), 171-185. doi: 10.1080/08993400802332423.

[26] Marton, F. \& Tsui, A. B. M. (2004). Classroom discourse and the space of learning. Mahwah, $\mathrm{NJ}$ : Lawrence Erlbaum Associates.

[27] Wright, M. (2005). Always at odds? Congruence in faculty beliefs about teaching at a research university. Journal of Higher Education, 76(3), 331-353.

[28] van Barneveld, A., \& Strobel, J. (2011, June). Innovative pedagogies in engineering education preliminary results from the teaching practices of American and Canadian educators. Paper presented at the 2nd Annual Canadian Engineering Education Association (CEEA) Conference, St. John's, NF. 